\title{
Ecological Framework of Information Interactions and Information Infrastructures
}

\author{
Isto Huvila ${ }^{1}$ \\ Department of ALM, Uppsala University, Uppsala, Sweden
}

\begin{abstract}
There has been notably little convergence between information organisation and information use studies. A framework for explicating the contextual interplay of information interactions and infrastructures of information, and more specifically the interface of information work and knowledge organisation systems is proposed. The theoretical foundations of the framework are based on systems theory and ecological approach. It is suggested that the interplay of information use and information infrastructures may be conceptualised as a systemic interaction, which is driven by the simultaneous influence of human activity related warrants and infrastructural affordances and constraints. The model provides an instrument that explicates the interplay of human information use and information infrastructures.
\end{abstract}

Keywords: Information interactions, information work, knowledge organisation, knowledge organisation systems, information infrastructures, ecological approach

\section{Introduction}

The polarities of information science research are a widely discussed issue [1][2][3]. Due to various reasons, there has been notably little convergence between information seeking and information retrieval studies [2][3][4], and between information/knowledge organisation (used here synonymously [5]) and information use studies [1][6]. One reason for this still prevailing state of affairs can be argued to be the lack of common frame of reference in terms of theories and scholarly orientation towards institutions, documentation and information [7]. Information systems have been able to meet only some information work and use related problems and the results of information use studies have proven difficult to operationalise in systems design.

The latter gap has been discussed relatively seldom in explicit theoretical terms. Steinerová [8] maps the human issues of information seeking and knowledge organisation (KO) and Abbott [9] discusses the general issue of subjectivity. Given and Olson [10] use data on information behaviour as a basis for constructing KO. The

1 Correspondence to: Isto Huvila, Department of ALM, Uppsala University, Box 625, SE-75126 Uppsala, Sweden, isto.huvila@abm.uu.se. 


\section{Isto Huvila}

practical aspects of the gap have received attention in digital library research [11]. Sonnenwald and Iivonen [12] used Ranganathan's framework for KO in their integrated human information behaviour research framework. In spite of the apparent possibilities to develop the model further to grasp integration of KO and information behaviours, the authors omit this aspect in their discussion.

Johnstone et al. [13] argue that one reason for the gap between information systems (and formal information) and human information behaviour discussion is the lack of attention to the human side of information processing. In order to bridge the gap between information systems and the human side in the context of work, Rasmussen, Mark-Pejtersen and their colleagues proposed an ecological approach denoted cognitive work analysis (CWA) in the early 1990's [14]. Albrechtsen and Pejtersen [15] have discussed the approach in the context of constructing classification schemes. Originally, CWA was developed as a distinct part of a wider framework known as cognitive systems engineering [16][17], and in information systems science, it has been used to address such topics as the evaluation and analysis of systems and collaborative work [18][19]. In information science, the principal advocates of the approach have been Fidel and Pejtersen (e.g. [20][19][21][22]). CWA is work centric approach and it describes information activity within individual contexts in order to improve the ways that how information is processed within those particular contexts. The approach has been effective in informing information systems design, but the emphasis of design and particular domains and work contexts limit its general applicability to understanding how information infrastructures and information interactions are related to each other. Design requirements are based on understanding, but the two do not substitute each other, as Feinberg [23] remarks while arguing for the need of more design emphasis in information science research. The second limitation of the CWA is that even though work is a major context for human activity and information behaviour, information seeking and use are simultaneously driven by multiple different 'works' and concurrent goals, such as personal interests and development, competing work duties, shared cultural values, meanings and purposes [24], and information and its structures [25, vii-viii].

In the present article a framework is proposed for explicating the second gap, the interplay of information interactions and infrastructures of information. More specifically the focus is on the interface of information work and knowledge organisation systems (KOS). The issues related to that particular interface have been discussed in the knowledge organisation and representation literature for decades [26, 27, 28, 23, 29]. Besides providing means to explicate their relation, the approach aims at providing conceptual tools for engagement in design of both information work practices and KOSs. Like in CWA, the theoretical foundations of the framework are based on ecological approach [30] that provides means for explicating the structure, functioning and evolutionary change of information work and information infrastructures. The notion of information use is discussed in the broadest possible meaning as to comprise information seeking and retrieval, applications of information to different purposes and the creation, storage and retrieval of information [31][32][33].

Typically the relation of systems and infrastructures is seen either as relatively static (e.g. warrants and KOS, [34][35][36]) and when the dynamic nature of their relation is underlined, the specifics of that dynamism have been described in somewhat loose terms [37]. The present article is based on an argument that an ecological [30] approach can provide a more robust framework for explicating complex causes and consequences and the evolutionary rather than abrupt change of the systems and infrastructures than an approach based on the existence of constants. The present approach builds on the Soft Systems Methodology (SSM) introduced by Checkland [38][39][40] and places a special emphasis on the implications of its post-structural stance. In systems thinking terms, the assumed standpoint is 'human-centred' [2][41] instead of being a formal one. Conceptually the suggested approach combines ecological theories (more specifically the Gibson's ecological approach and the concepts of affordance and constraint [42][43][44]) and the concept of warrants [34, 35, 36] used in information science literature to explicate the relation of $\mathrm{KO}$ and information work. In this article it is suggested that the two notions are related and the interplay of information use and information infrastructures may be conceptualised as a systemic interaction, which is driven by the simultaneous influence of human activity related warrants and infrastructural affordances and constraints. The proposed framework (illustrated in Fig.1, discussed in detail below) provides an instrument to describe interplay of human information use and information infrastructures. The present model is based on an earlier version of the framework developed as a part of the doctoral thesis [52] of the author. 


\section{Isto Huvila}

\section{Work}

The baseline of the proposed approach is the notion of work (Fig. 1). Generally speaking, work is a vague concept without a clear definition. The general phenomenon of work grasps broadly the various modes of working, including the colloquial everyday work and work practises [45][46]. In the present article, it is assumed that the 'work', as an activity with purpose, meaning and value, forms a theoretical system encompassed by (in a relative sense) multiple secondary, mutually overlapping systems. The general understanding of the notion of work follows that of Strauss and Star [47][48]. Work, its underpinnings, objectives and implications differ between individuals and it is construed through an individual and collective goal attainment, encodings and attitudes [49][50][51] as well as through a direct activity of organising and steering. Generally speaking, the understanding of the concept of "work" is normally shared in a community, but the understanding of any distinct instance of work as 'work', does not need to be shared in its entirety [48]. An activity may be simultaneously considered by different individuals to be and not to be work.

According to an essentially Straussian [47] notion of work developed further by Huvila [52], work and its components are not related to each other in simple linear chains, nor do they form a completely undecipherable mess. Work follows certain, although often merely implicit, rules and codes, which relate to each other in complex, but still organised processes and lines of actions. In spite of its seeming randomness, the human work tends to present a degree of coherence and attain some scripted objectives.

The concept of work is related closely to the notion of work task in the sense it is discussed in the information science and information systems science literature [53][48][54][55][56][57][58][3]. Compared to a work task, work is essentially a meta-concept, which is potentially inclusive of individually identifiable work tasks. Work is basically an upper level activity, which ties individual work tasks together and makes them 'work tasks' instead of mere 'tasks' [52, 21]. Strauss [47] denotes this the "arc of work".

\section{Information work}

Nurminen has argued that abstract notions of information work tend to be more productive viewpoints within the context of socially and culturally oriented analyses of information and work, than the technological ones [59, 170]. In general, the critique of Elliman and Hayman [60] on the use of the concept 'knowledge work' could be extended to information work as well. Technological viewpoints consider information work as a work, which involves information technology, while the more abstract information centric definitions emphasise the role of 'information' and its epitomes [59] as e.g. in [61]. A third category of information work is the colloquial use of 'information work' and the related concept of 'eWork', which [62] denote explicitly information related professions (e.g. library, ICT, archives) [63, 4][64, 4][65, 4][66, 4].

Within LIS, Palmer has used 'information work' in an abstract meaning "as a general term to refer to information practices at any of these levels of granularity" [67]. The notion of information work assumed in the present discussion is similarly classifiable as being abstract. The concept grasps all activity, which relates to the cultural-contextual category of information. Information work may be work in a traditional sense, but in addition, it may be used to refer to any other activity, which conforms to the notion of work discussed earlier. Unlike in the work system method (WSM) and similar information systems oriented viewpoints, the information work (system) is seen a constituent component of work (system) [68]. In short, it may be argued that all work has an information component and presume some degree of information processing whether the work is manual labour or highly abstract decision making. In library, archive and related visible information intensive work, information work is primary activity [33]. More often, however, like information need is seen as a secondary need by Wilson [69] and information-seeking activities are seen by Byström and Hansen as sub-tasks for the primary purposes or goals of a work task [57, 1052], information work could be described as being equally infrastructural within the work (Fig. 1), and being, in a sense, 'sub-work'. 


\section{Isto Huvila}

Besides being a component work, information work relates also to the notion of information behaviour [70][24][33]. While the principal underpinning of information work is work, an activity, the primary focus of information behaviour is on individual or community actors. In a sense, information work may be conceptualised as a manifestation of participating information behaviours in an instance of work.

Information work is largely faced with the same problems of visibility than the invisible work discussed by Star and Strauss [48]. Information work is embedded and layered, and it is difficult to manage due to its various levels of articulation and its conditional visibility. Because the information work is largely 'invisible', it needs to be made explicit to become valued accordingly to its societal impact [71][72][48][73][74]. Otherwise, an inefficient and ineffective information work risks becoming a major impediment in work processes.

\section{Information infrastructures and knowledge organisation systems}

Information infrastructures and KOSs (Fig. 1) are two distinct, yet intricately related concepts. KO has been a prominent research topic in the information and documentation studies for some decades (e.g. [75]). The traditional focus of the investigation has been on enabling efficient retrieval by developing indexing and classification of information resources. The theoretical foundations of this principally rather practical topic may be found in diverse traditions. Those include taxonomy, epistemology, ontology, semiotics and theoretical linguistics. The accelerating shift towards ICT-based KOSs has turned the researchers' attention increasingly towards the computer related topics such as database theory, data structures, automatic indexing algorithms and the Semantic Web [76, 24][77, 24][78, 24].

As a whole, KO may be described as a process of identifying and subsequently describing objects of knowledge dissemination, their content, features and meaning. The discovered identifications and descriptions are thereafter organised in indexes, catalogues and other organisational frameworks, which are denoted collectively as KOS [78]. Even though the definitions of KOSs tend to focus on the mentioned kinds of explicit and distinct efforts of organising knowledge, all collections of information resources implement some type of embedded KOS. The system can be based on identification numbers on data files, table of contents in a book or a specific structure of a document. Also in these cases, the focus is on describing objects of knowledge dissemination, their content, features and meaning in their context of appearance.

The basic understanding of an information infrastructure as a subsurface fabric formed by available information resources and their organisation at a given instance follows the viewpoint of Bowker and Star [43]. An information infrastructure is established by its use and usability for the purposes of communicating information. Information infrastructures have been referred to both explicitly and implicitly in a more extensive manner in the ethnographically oriented information systems literature [79], whereas KOS is fundamentally an information science concept [78]. Information infrastructure is essentially a broader concept than 'knowledge organisation system'. An infrastructure is a carrier and a premise for the existence and movements of information and knowledge between individuals, groups and organisations. In a general sense, the term has been used of the world wide computerised information networks [80], information technology infrastructures, of the entirety of the commonly available information repositories [81], and of the cyberspace communities, multi-user dungeons, and comparable structural premises for information interactions [82]. Information infrastructures are the tools, words, categories and information processing procedures for the information work [83], whereas a KOS is a systematic and confined representation. Unlike an information infrastructure, it is never an open uncontrolled milieu.

Because of the systematic and constructed nature of a KOS, it is also an attempt to control and to make its underlying information infrastructures explicit and visible. Bowker and Star perceive classificatory schemes as instances of infrastructures [43] (see also [84][85]), but classificatory schemes, as well as the other KOSs, can also be seen as infrastructural candidates (i.e. potential infrastructures), which are imposed on the existing infrastructures in order to make them explicit. They are controlled and constructed knowledge structures and controlling instruments for management of information activities. The explicit goal of classification schemes is to resist the characteristic of infrastructures [42] that they may never be changed from above. Infrastructures are not top-down, they rather evolve and change in a semi-autonomous manner and as Star and Ruhleder describe, noone 


\section{Isto Huvila}

is really in charge of an infrastructure [79]. Classificatory schemes are, in contrast, attempts to explicitly steer and take a charge of an infrastructure (Fig. 1). They are infrastructures themselves and can be used as such. Further, as devices of control they have consequences on their underlying and related infrastructures and to the work they support [43]. Gibsonian ecological approach has referred to the notions of affordances and constraints [30] to explicate how an infrastructure (i.e. according to earlier discussion, for instance, a KO) permits and restrains certain activities.

The existence of a KOS has two prerequisites that there is something to organise and there is organisation according to something. According to an implicit consensus of LIS research, without making a specific case of what information/knowledge is, it is something which can processed, retrieved and organised at least to a degree, either in a direct or in an indirect (e.g. in form of knowledge representations or resources [5]) manner [3][28][29][52]. The notion of organising, on the other hand, presumes an organisation according to something. Perceiving an order requires that there is a perceived ordering principle. Therefore, information always needs to be organised according to some theoretical principle explicated to form a KOS [29]. In a strict sense, the principle does not need to be constructed when constructing a KOS. In that respect the act of constructing a KOS is not an act of bringing order to an in-orderly information infrastructure, but a conditional act of interpreting the existing order. Constructing a KOS presupposes, however, a compulsory act of explicating the organisation in terms of an outspoken principle, which is typically an assemblage of more or less explicit forms of criteria than a monolithic entity. The principle (e.g. alphabetical order) collects the individual criteria (b comes after a, c comes after b etc.) together and constitutes an orderly compilation [86]. According to the currently prevalent subjectivist understanding of knowledge, KOSs are fundamentally artificial constructions [87]. Determination of the organisation criteria and the semantic relations of objects are based on a series of subjective choices, not on a straightforward observation [88]. Even though this standpoint basically denies the possibility of an objective basis of the KO, the reaching of a functional and especially shareable organisation scheme requires some rationalisation in the form of shared criteria. The KOS needs to be warranted in order to exist.

\section{Warrants}

Hulme introduced the concept of a 'literary warrant', which expounded on a principle that the criteria of organising knowledge in any particular manner, have to be present in the literature. Thereafter the notion of the literary warrant has become focal in the discussion on $\mathrm{KO}$ [34][35][36], although the precise view on its essential meaning has varied from one author to another [86]. In spite of some critique, the concept of 'warrant' has been adopted widely as a practicable concept to denote the intellectual criteria of KO [37] (Fig. 1). To replenish the approach, the scholarly discourse has assumed several complementary warrants such as user warrant, logical warrant [34], phenomenological warrant [89], cultural warrant [86] and using work domain as a warrant [15]. The various warrants raise an immediate question on their respective interrelations and how it might be possible to found a single KO scheme on multiple warrants. Combining the different warrants is not straightforward. Svanberg points out, however, that the diverging warrants may be used to complement each other [37].

Besides complementing each other, warrants may be contrary to each other. Beghtol introduced the concept of hospitality to address the issue of the coexistence of the warrants. Hospitality refers to the ability of a KOS to incorporate new concepts and to found new semantic and syntactic relationships between the existing and the new structures [90]. In a slightly broader sense of meaning, the concept of hospitality may be used to denote an ability to incorporate both intra and inter warrant differences i.e. eventual changes within and between individual warrants. A hospitable KOS is aware of them and is prepared to cope with them in an efficient and, in a sense, 'respectful' manner.

The constituent benefit of using the warrants as a theoretical framework for discussing the premises of KO (Fig. 1), is the possibility to explicate the existing forcing criteria and to understand their semantic underpinnings [88]. The criteria may function both as analytical tools and as frameworks for design KOSs. 


\section{Isto Huvila}

\section{Affordances and constraints}

The capacity of systems to permit and encourage some activities simultaneously prohibit and prevent some others are often referred to as affordances and constraints. The concepts are rooted in the ecological approach of Gibson, which originates in the context of cognitive psychology [91][30]. The notion of an ecological constraint refers to the structures of the external world, which guide human action, in contrast to the persons' internal cognitive processes. Gibson [92, 127] uses 'affordance' to denote "what an environment offers an animal, what it provides and what it furnishes" (see also [91][30]).

Of the two Gibsonian concepts, the affordance has been widely popular in human-computer interaction (HCI) research especially since the publication of the influential The psychology of everyday things by Norman in 1988 [93]. However, the understanding of affordances in Norman and especially in the later HCI literature, differs rather significantly from the original Gibsonian notion [94]. The references to the ecological approach in the HCI literature have been criticised of referring to affordances in a simplistic and an acontextual manner as 'direct invitations' to act in a distinct manner [94][95]. In spite of the critique, the HCI researchers, who discuss the complexities of human - information system relationship in terms of affordances, have to be credited with placing emphasis on the need to articulate user and usage issues in information systems design [95]. The same issues may be argued to be of importance also in the context of designing KO. KOSs are, nonetheless, first and foremost meant to be usable instruments to the humans.

Ecological approach has been discussed in information science literature by several researchers. Cognitive work analysis refers also to the Gibsonian ecological approach, but focuses solely on constraints [19]. Williamson [96] propose an ecological model of information acquisition and Nardi and O’Day [97] discuss information ecologies as systems of people, practices, values, and technologies in a particular local environment. Sadler and Given [98][99] have used affordances to discuss the use and non-use of intended and unintended services of academic libraries assuming a stance of the theory, which is very close to the version appearing in the HCI literature. Affordance is considered by Sadler and Given to be a direct invitation [94] or even a direct offering [98][98]. Vatanen [44] has discussed the relation of $\mathrm{KO}$ and information use in terms of affordances and constraints.

\section{Ecologies of information work}

The proposition that the notions of warrants, affordances and constraints form a practicable basis for understanding the systemic formation and situatedness of the knowledge is based on a seemingly trivial notion that an eventual knowledge claim (in Hjørlandian [100] sense, instead of referring to the positivist and rather commodifying notion of knowledge resources) is dependent on its referential data. In spite of that the outcome of the process of making a knowledge claim out of pre-existing information is far from being unambiguous. In a sense, the knowledge claims are at the present potential, but in a sense non-actual, or virtual [107] objects, which generate relationships that closely resemble ecological affordances and constraints. The process of collecting information does not end up in a single predestined knowledge claim. Reasons for a particular variation may be found, for instance, in individuals and their cognitive processes, and in the social context of the process. Besides the information process, also the structural factors of form, organisation and presentation of the claims affect the outcome. These infrastructural characteristics (formation process, structure, and functionality of any individual KOS) can be considered to afford certain distinct types of secondary knowledge claims to take shape. Respectively, certain competing knowledge claims can be considered to be more unlikely to emerge within the confines of a given system than some others. Information and KOSs possess a capacity to promote, either explicitly or implicitly, some information to become more prominent than some other. The functional characteristics of the system and the chosen practises of $\mathrm{KO}$ steer the outcome of queries and ultimately, the information provided by the system (Fig. 1). The combined understanding of the affordances, constraints and warrants are keys to informed design and implementation of changes in both KOSs and the practices of information work. 


\section{Isto Huvila}

In an empirical study of Finnish and Swedish archaeology professionals Huvila [52] ${ }^{2}$ points out that even though the contemporary archaeological research tends to prioritise social and cultural dimensions of the past when contemplating archaeological remains, the process of documentation and especially of storage and archival of the preserved objects, impedes addressing these precise questions. The catalogues and publications afford primarily research outlined by a classification of archaeological finds according to their material (e.g. clay or iron), the size of the objects and their provenance. In contrast, the existing KO does not nurture phrasing of questions on functional categories or visual characteristics of objects [52, 239]. Similar difficulties are immanent with research designs aiming at comparisons between various archaeological sites, locations and periods. Such attempts are practicable only in the rare projects with enough resources for years of laborious studies and accumulation of the designated researchers' experience and knowledge on the materials.

According to the study [52], the prevailing, relatively antiquarian, data management procedures seem to be warranted by the assumed priorities of the work that tend to be guided by the manageability of the primary operations (i.e. investigation and documentation). The assumed original functions and perceived visual characteristics of the objects are necessarily more subjective notions than the quantitative observations that prevail in the documentation work. The weight of an object is standardisable and therefore, the documented characteristics are likely to show only slight variation between the individual observations. The quantitative data is also easier to produce, store and manage than in-depth interpretations. This makes quantitative documentation to be a practical choice for archaeologists who are first and foremost expected to file formally correct reports and documents, instead of using them immediately in scholarly research or public presentation [52, 239-240].

MacIntosh-Murray and Choo [101] discuss a case study of nurses in a Canadian teaching hospital. The authors suggest several reasons why nurses seem to be 'doers' occupied with 'coping from shift to shift' by firstorder problem solving and why it is difficult to facilitate changes to improve patient safety. The information practises of nurses are based on oral communication and avoidance of written instructions and documentation. The practises were motivated by efficiency of oral briefings and asking colleagues, and the lack of time to focus on less relevant written information. Computers, patient records and printed documents were used when it was the expected standard of practise. The main sources of literary information were practise leaders/educators who worked as mentors for the nurses. They were present at the units and represented a neutral party not being part of the management. More over the practise leaders/educators had time to focus both on nursing work and on information seeking. They could function as boundary spanners, information seekers, knowledge translators from the literature and documents to the oral world of nurses and consequently as 'change champions' of the work routines. MacIntosh-Murray and Choo identified seven dimensions: the focus on 'coping from shift to shift', lack of critical thinking, accountability meaning responsibility, focus on people instead of processes, message-method mismatch regarding improvement, issues of power, voice and boundaries, and the situatedness of nursing practises [101].

In addition to the ones discussed by MacIntosh-Murray and Choo, another dimension may be discerned when information activity and interactions are explicated from an ecological point of view. The oral communication practises warranted the existence of practise leaders/educators, who could brief nurses at the units. The central role of practise leaders/educators as information gateways and change agents facilitated nursing work, but same time their functioning as an information infrastructure, may be suggested to have afforded the described kind of oral information culture and constrained any motivation to consult literature.

When discussing the affordances and constraints of the information management and $\mathrm{KO}$, there is a distinction to be made between surrogate level infrastructural aspects and the characteristics relating to the form and structure of the data itself. As one of the informants of Huvila [52, 240] expressed, the archaeological view of the past tends to privilege object-centric interpretations of human thinking and activity, while the historians perceive the past often as a conspicuously literary, in spite of the frequent explicit theoretical undertakings to alter this viewpoint. These tendencies do not relate to the affordances and constraints posed by a system of organising information, but to the form of the information objects themselves. It is reasonable to suggest that the material remains are bound to privilege materialistic interpretations and oral sources privileges oral information practises in the case of nurses. The physical form of an artefact may be described as an infrastructural characteristic of a

\footnotetext{
${ }^{2}$ See [52] for a detailed discussion of the results and methods of the study.
} 


\section{Isto Huvila}

first level of abstraction. Similarly to its other qualities, the form represents a set of constraints and affordances. Equally meaningful source of essentially different affordances and constraints is, however, the archaeological KOS, which is used to describe and classify the physical data in order to alleviate its further use. The infrastructural level of $\mathrm{KO}$ is capable of removing the constraints of the first (physical) level. The prevailing efforts to describe the physical world using conspicuously different e.g. textual and graphic representations do provide affordances to pass some of the hindrances of the physical constraints, but does not per se empower the use of the physical data.

The two examples were used to pinpoint the contribution of the ecological approach to the KO research. The approach can help to make the diverse contextual premises and consequences of the $\mathrm{KO}$ and (information) work explicit in the form of constraints and affordances and warrants. The ecological viewpoint alleviates the inclusion of mutually dissimilar descriptions and the simultaneous exploration of diverse schemes for organising the data. The questions of choosing an appropriate content and explicating a purpose for the provision of additional information may be based on a more precise motivation of tendering distinct affordances, which serve the users of the information. Similarly, the constraints may be lifted or maintained on a more warranted basis than by resorting to a guess of the user needs and behaviour or to a semi-informed design decision. The ecological analysis of information work and KOSs does not eliminate the need for conscious design decisions underlined by Feinberg [23]. It provides means to make the decisions well defined, in the sense Haraway [102] describes her notion of situated knowledges. In practical terms, an ideal KOS should be warranted by its referential information work, it affords desired kind of information work and constrains unwanted information work practices. The functioning of the infrastructure needs to embed and recognise the affordances and constraints posed by the data that originate from the cognitive, social and cultural contexts and situations, in order to become warranted in the frame work provided by the notion of work.

\section{Infrastructures and information work}

The relevance of the proposed ecological approach for the $\mathrm{KO}$ lies in the possibility to examine the knowledge formation and the processes of organising and using knowledge as interlinked and contextually anchored projects similarly to Chatman's perception of information seeking [103]. This is in contrast to seeing KO and information work as series of actions related to a 'thing' called information/knowledge or a knowledge claim. Similarly the framework provides means to consider the consequences of KOS to information work and consequences of information work to KOS together. A KOS is embedded as an infrastructure in a common system with the activities of information work and work. KO should be included to the general system of work, in a similar manner than Eriksson and Nurminen argue that a computerised information system is an inherent part of the work of the users [104].

Simultaneously to being warranted by information work, KO is bound to shape it according to the ecology of the entire system. Infrastructures shape the users' or participants' world view and information work by empowering and suspending the likelihood of the emergence of certain knowledge claims. An individual system of organising knowledge affords certain aspects and instances of information work and constrains others, forming eventually a circular system of warrants, affordances and constraints. The interrelationship of KO, infrastructures, warrants and ecological affordances and constraints is illustrated in the figure 1 . The cyclical system of information infrastructures and systems of information work are perceived in the present proposal to constitute a meta-system, which incorporates infrastructures, $\mathrm{KO}$ and information activities. Information work is considered to be 'sub-work', a part of work, as discussed earlier. Besides forming an infrastructure for work and information work (diagram should be read bottom to top: work and information work are situated on their underlying KOSs and infrastructures), the KOS is simultaneously warranted by its underlying information work. Information infrastructure forms a candidate KOS (arrow and dotted line to KOS). Hospitality functions as a modulator that accommodates different warrants, affordances and constrants together in an evolving KO. It ties together the warrants, affordances and constraints related to the convergence of KOS and work, and also other conceivable warranting, affording and constraining factors outside the scope of the present discussion. A hospitable KOS 


\section{Isto Huvila}

constructs a distinct set of ecological affordances and constraints based on its warrants beyond the original knowledge claims. In this perspective, a KOS is not as much a system of organising objects titled as knowledge claims, but a system of constructing an environment of affordances and constraints, which is usable in warranted knowledge formation.

The cycle of information work and information infrastructures maps to Choo's cyclical view of organisations as knowledge creating enterprises [106]. The warranted construction of information infrastructures is essentially a form of externationalisation of things known, whereas the use of the infrastructures in information work is about internalising and exploiting the codified infrastructural resource. The cause maps and diagramming discussed by Choo [106] are less formal and more ad hoc infrastructures than formal KOSs such as complex catalogues, classifications or ontologies. Essentially, they do still represent infrastructures based on actual sense making of the environment, i.e. active information work in the corporate contexts. Similarly to warrants, affordances and constraints, Choo [106] describes how successful practises can be abstracted to formal understanding and to warrant new designs (as in the well-known case of beer-cans and Canon copier cartridge design, and how codified formal knowledge can be used to afford information work like the GE’s Answer Desk knowledge base).

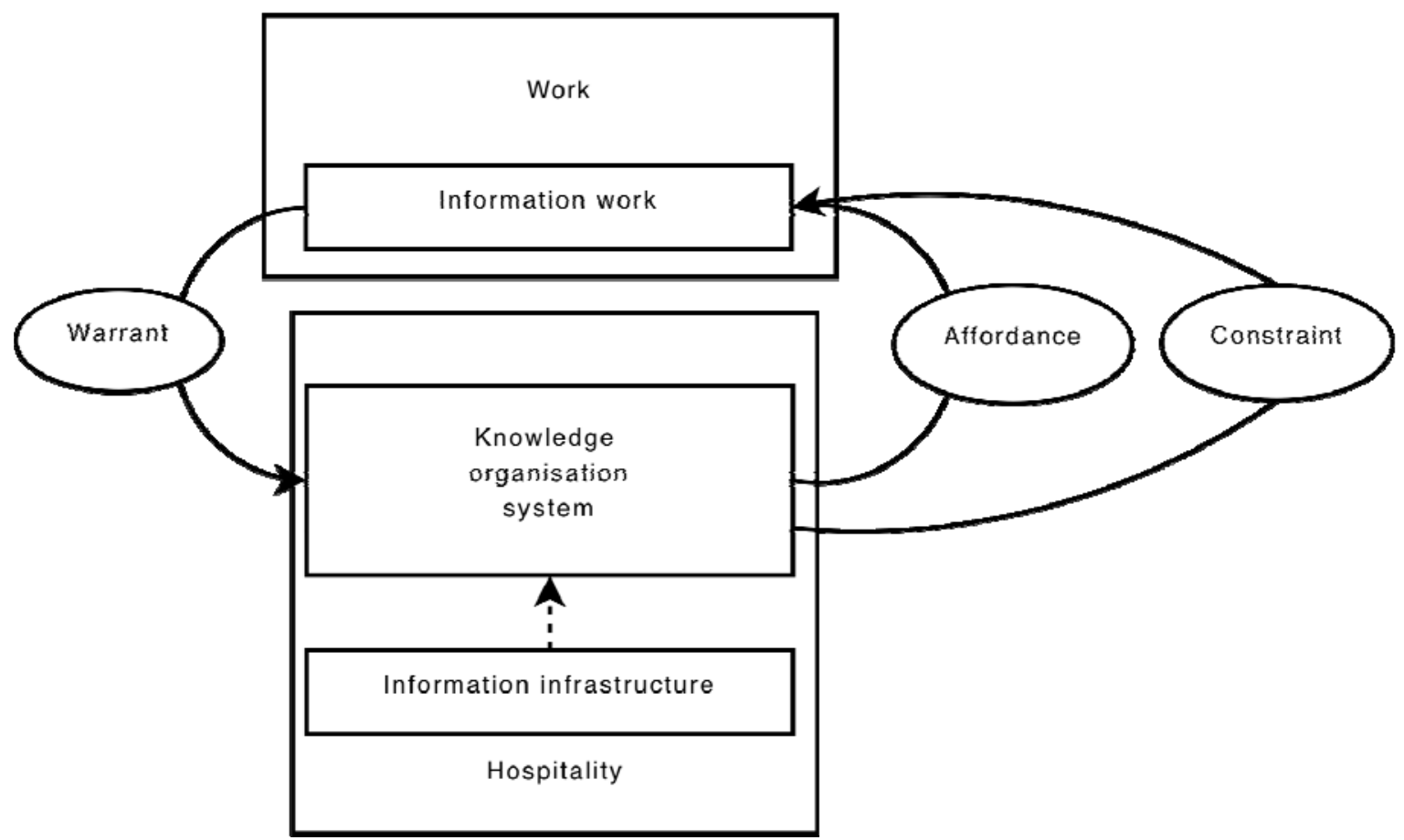

Figure 1. Ecology and warrants of information and knowledge organisation (KO)

The cyclical view of KOS and information work illustrated in figure 1 has several practical and theoretical implications. The convergence of a KOS and work is not based on the interplay of two static notions of how knowledge and work are organised, but on the existence of immediate consequences of KO to human activity and similarly effects of human activity to KO. As Feinberg [23] and Hjørland [29] note, all knowledge structures are constructs and therefore biased even within distinct discourse communities. The source of this bias is the forms and instances of information work that made them to exist and warrant their existence. KOs are not documentation of true reality and thus prone to advocate either explicitly or implicitly a viewpoint. KO can be based on (information) work like Nielsen [105] suggests on thesaurus construction and work tasks. Same time, however, the same and other instances of information work become altered as a consequence of the KO [43].

Besides the theoretical implications, the proposed framework can be used to explicate the consequences and causes of implementing KOSs, like the potential of virtual reality based knowledge organisation in archaeological information work [52]. Similarly it could be used to explicate the effectiveness and usability of KO approaches in other domains. The approach has also implications on systems design. The framework provides means to 


\section{Isto Huvila}

conceptualise how KOS links to information work, but also how the users are likely and unlikely to use the KOS in terms of affordances (what uses and misuses the system invites to consider) and constraints (what uses and misuses are discouraged or inhibited by the system). A practical drawback of the approach is that it requires a relatively thorough understanding of the KOS and information under scrutiny. In [52] the material was gathered using thematic interviews, but ethnographic observation and related rich data gathering methods can be suggested to function as well. Developing a less time consuming survey instrument for gathering adequate data is a major goal of future research.

\section{References}

[1] Michael Buckland. The landscape of information science: the American society for information science at 62. Journal of the American Society for Information Science, 50(11):970-974, 1999.

[2] Tefko Saracevic. Information science. Journal of the American Society for Information Science, 50(12):1052-1053, 1999.

[3] Peter Ingwersen and Kalervo Järvelin. The Turn: Integration of Information Seeking and Retrieval in Context, volume 18 of The Information Retrieval Series. Springer, 2005.

[4] Carol C. Kuhlthau. Towards collaboration between information seeking and information retrieval. Information Research, 10(2), January 2005.

[5] Jack Andersen. Analyzing the role of knowledge organization in scholarly communication: An inquiry into the intellectual foundation of knowledge organization. PhD thesis, Royal School of Library and Information Science, Copenhagen, 2004.

[6] Jeremy Gow, Ann Blandford, and Sally Jo Cunningham. Special issue on digital libraries in the context of users' broader activities. Information Processing \& Management, 44(2):556-557, 2008.

[7] Birger Hjørland. Library and information science: practice, theory, and philosophical basis. Information Processing \& Management, 36(1):501- 531, 2000.

[8] Jela Steinerová. Human issues of library and information work. Information Research, 6(2), January 2001.

[9] Robert Abbott. Subjectivity as a Concern for Information Science: A Popperian Perspective. Journal of Information Science, 30(2):95-106, 2004.

[10] Lisa M. Given and Hope A. Olson. Knowledge organization in research: A conceptual model for organizing data. Library \& Information Science Research, 25(2):157-176, 2003.

[11] Jela Steinerová. In search for patterns of user interaction for digital libraries. In Research and Advanced Technology for Digital Libraries, volume 2769 of LNCS, pages 13-23, Berlin, 2003. Springer.

[12] Diane H. Sonnenwald and Mirja Iivonen. An integrated human information behavior research framework for information studies. Library and Information Science Research, 21(4):429-457, 1999.

[13] David Johnstone, Mary Tate, and Marcus Bonner. Bringing human information behaviour into information systems research: an application of systems modelling. Information Research, 9(4), July 2004.

[14] Kim J. Vicente. Cognitive Work Analysis: Towards Safe, Productive, and Healthy Computer-Based Work. Lawrence Erlbaum Associates, Inc., Mahwah, NJ, USA, 1999.

[15] H. Albrechtsen and A.M. Pejtersen. Cognitive work analysis and work centered design of classification schemes. Knowledge organization, 30(3- 4):213-227, 2003.

[16] Jens Rasmussen. Information Processing and Human-Machine Interaction: An Approach to Cognitive Engineering. Elsevier Science Inc., New York, NY, USA, 1986.

[17] Jens Rasmussen, Annelise Mark Pejtersen, and L. P. Goodstein. Cognitive systems engineering. John Wiley \& Sons, Inc., New York, NY, USA, 1994. 


\section{Isto Huvila}

[18] Annelise Mark Pejtersen and Jens Rasmussen. Cognitive work analysis of new collaborative work. In SMC (1), pages 904-910, 2004.

[19] Raya Fidel and Annelise Mark Pejtersen. From information behaviour research to the design of information systems: the Cognitive Work Analysis framework. Information Research, 10(1), 2004.

[20] A. M. Pejtersen. A library system for information retrieval based on a cognitive task analysis and supported by an icon-based interface. In SIGIR '89: Proceedings of the 12th annual international ACM SIGIR conference on Research and development in information retrieval, pages 40-47, New York, NY, USA, 1989. ACM Press.

[21] Raya Fidel, Annelise Mark Pejtersen, Bryan Cleal, and Harry Bruce. A multidimensional approach to the study of human-information interaction: a case study of collaborative information retrieval. Journal of the American Society for Information Science and Technology, 55(11):939- 953, 2004.

[22] R. Fidel and A.M. Pejtersen. Cognitive Work Analysis. In Karen E. Fisher, Sanda Erdelez, and Lynne E.F. McKechnie, editors, Theories of information behavior: A researcher’s guide. Information Today, Medford, NJ, 2005.

[23] Melanie Feinberg. Hidden bias to responsible bias: an approach to information systems based on Haraway’s situated knowledges. In Proceedings of the Sixth International Conference on Conceptions of Library and Information Science - Featuring the Future, 2007.

[24] Donald O. Case. Information behavior. Annual Review of Information Science and Technology (ARIST), 40:293-327, 2006.

[25] Peter Pirolli. Information Foraging Theory: Adaptive Interaction with Information. Oxford University Press, Oxford, 2007.

[26] B. Frohmann. Rules of indexing: a critique of mentalism in information retrieval theory. Journal of Documentation, 46(2):81-101, 1990.

[27] Birger Hjørland and Hanne Albrechtsen. Toward new horizon in information science: Domain analysis. Journal of American Society for Information Science, 46(6):400-425, 1995.

[28] Birger Hjørland. Documents, memory institutions and information science. Journal of Documentation, 56(1):27-41, 2000.

[29] Birger Hjørland. Deliberate bias in knowledge organization? Advances in Knowledge Organization, 11:256-261, 2008.

[30] James J. Gibson. The perception of the visual world. Houghton Mifflin, 1979.

[31] Robert Taylor. Information use environments, pages 217-255. Progress in Communication Sciences, volume 10, Ablex, Norwood, NJ, 1991.

[32] T.D. Wilson. Human Information Behavior. Information Science Research, 3(2):49-55, 2000.

[33] Amanda Spink and Charles Cole. Human information behavior: Integrating diverse approaches and information use. Journal of the American Society for Information Science and Technology, 57(1):25-35, 2006.

[34] W. J. Fraser. Literary, user and logical warrants as indexing constraints. In E. H. Brenner, editor, The information age in perspective: Proceedings of the ASIS Annual Meeting, pages 130-132. Knowledge Industry Publications, 1978.

[35] R. D. Rodriguez. Hulme's concept of literary warrant. Cataloging \& Classification Quarterly, 5:17-26, 1984.

[36] Clare Beghtol. Domain analysis, literary warrant, and consensus: The case of fiction studies. Journal of the American Society for Information Science, 46(1):30-44, 1995.

[37] Magdalena Svanberg. Classification, warrants and principles. Swedish Library Research, (2-3):66-75, 1996.

[38] Peter Checkland. Systems thinking, Systems practise. Wiley, New York, 1981. 


\section{Isto Huvila}

[39] Peter Checkland and Jim Scholes. Soft systems methodology in action. Wiley, New York, 1990.

[40] Peter Checkland. Soft systems methodology - a thirty year retrospective. Systems Research and Behavioral Science, 17(1):11-58, 2000.

[41] Ervin Laszlo and Alexander Laszlo. The contribution of the systems sciences to the humanities. Systems Research and Behavioral Science, 14(1):5-19, April 2000.

[42] Susan Leigh Star and Karen Ruhleder. Steps towards an ecology of infrastructure: complex problems in design and access for large-scale collaborative systems. In CSCW '94: Proceedings of the 1994 ACM conference on Computer supported cooperative work, pages 253-264, New York, NY, USA, 1994. ACM Press.

[43] Geoffery C. Bowker and Susan Leigh Star. Sorting things out: classification and its consequences. MIT Press, Cambridge, MA, USA, 2000.

[44] Isto Vatanen. Affordances and constraints in knowledge organization. In Suliman Hawamdeh, editor, Knowledge Management: Nurturing Culture, Innovation and Technology. Proceedings of the 2005 International Conference on Knowledge Management, pages 315-321, Singapore, World Scientific, 2005.

[45] Graham Button and Richard Harper. The relevance of work-practice for design. Computer Supported Cooperative Work, 4(4):263-280, 1996.

[46] Helena Karasti. Bridging the analysis of work practice and system redesign in cooperative workshops. In DIS '97: Proceedings of the conference on Designing interactive systems, pages 185-195, New York, ACM Press, 1997.

[47] Anselm Strauss. Work and the division of labor. The Sociological Quarterly, 26(1):1-19, 1985.

[48] Susan Leigh Star and Anselm Strauss. Layers of silence, arenas of voice: The ecology of visible and invisible work. Computer Supported Cooperative Work, 8(1-2):9-30, 1999.

[49] R. Brown. How shall a thing be called? Psychological Review, 65:14-21, 1958. [

50] Max Weber. Sociological theory : a book of readings, chapter Subjective meaning in the social situation, pages 209-221. Macmillan, London, 1970.

[51] R. H. Fazio. Advances in experimental social psychology, chapter Multiple processes by which attitudes guide behavior: The MODE model as an integrative framework, pages 75-109. Academic Press, New York, 1990.

[52] Isto Huvila. The ecology of information work - A case study of bridging archaeological work and virtual reality based knowledge organisation. Åbo Akademi University Press, Åbo, 2006. Diss. Åbo Akademi University.

[53] Les Gasser. Integration of computing and routine work. ACM Transactions on Office Information Systems, 4(3):205-225, July 1986.

[54] Pertti Vakkari. Task complexity, problem structure and information actions. integrating studies on information seeking and retrieval. Information Processing \& Management, 35:819-837, 1999.

[55] C. Cole and C. Kuhlthau. Information and information seeking of novice versus expert lawyers: how experts add value. New Review of Information Behaviour Research, 1(1):103-115, 2000.

[56] Pertti Vakkari. A theory of the task-based information retrieval process: a summary and generalisation of a longitudinal study. Journal of Documentation, 57(1):44-60, January 2001.

[57] Katriina Byström and Preben Hansen. Conceptual framework for tasks in information studies. Journal of the American Society for Information Science and Technology, 56(10):1050-1061, August 2005.

[58] Luanne Freund, Elaine G. Toms, and Julie Waterhouse. Modeling the information behaviour of software engineers using a work - task framework. Proceedings of the American Society for Information Science and Technology, 42, 2005.

[59] Markku I. Nurminen. People or computers : three ways of looking at information systems. Studentlitteratur and Chartwell-Bratt, Lund / Bromley, 1988. 


\section{Isto Huvila}

[60] A. D. Elliman and A. Hayman. A comment on kidd's characterisation of knowledge workers. Cognition, Technology \& Work, 1(3):162-168, November 1999. [61] Antti Oulasvirta and Lauri Sumari. Mobile kits and laptop trays: managing multiple devices in mobile information work. In CHI '07: Proceedings of the SIGCHI conference on Human factors in computing systems, pages 1127-1136, New York, ACM, 2007.

[62] Nick Jagger. Will the convergence of nace and naics in 2007 solve ework measurement problems? Working Paper WP3, STILE project IST-2000- 31099, September 2002.

[63] Paul A. Strassmann. Information Payoff: The Transformation of Work in the Electronic Age. Strassmann, Inc., 1985.

[64] Marc Uri Porat. The information economy : definition and measurement. U.S. Dept. of Commerce, Office of Telecommunications, Washington, D.C., 1977.

[65] David Smith. Systems thinking in library and information management. K. G. Saur / Clive Bingley, New York - London - München - Paris, 1980. IIF.

[66] Julian Newman. Some observations on the semantics of 'information'. Information Systems Frontiers, 3(2):155-167, 2001.

[67] Carole L. Palmer, Melissa H. Cragin, and Timothy P. Hogan. Weak information work in scientific discovery. Information Processing \& Management, 43:808-820, May 2007.

[68] Steven Alter. The work system method for understanding information systems and information systems research. Communications of the AIS, 9(Article 6), September 2002.

[69] Tom Wilson. On user studies and information needs. Journal of Documentation, 37(1):3-15, 1981.

[70] Karen E. Fisher, Sanda Erdelez, and Lynne E.F. McKechnie, editors. Theories of Information Behavior. Information Today, Medford, NJ, 2005.

[71] Susan Lee Star. Invisible work and silenced dialogues in knowledge representation. In I. Eriksson, B. Kitchenham, and K. Tijdens, editors, Women, Work and Computerization, pages 81-92, Amsterdam, 1991. New Holland.

[72] Lucy Suchman. Making work visible. Communications of the ACM, 38(9):56-64, 1995.

[73] Lucy Suchman. Located Accountabilities in Technology Production. Centre for Science Studies Lancaster University, 2000-2003.

[74] Lucy Suchman. Making a case: 'knowledge' and 'routine ' work in document production, In Workplace Studies: Recovering Work Practice and Informing System Design, pages 29-45. Cambridge University Press, Cambridge, 2000.

[75] John Dewey. Introduction. In Henry Evelyn Bliss. The organization of knowledge and the system of the sciences, pages vii-ix. Holt, New York 1929.

[76] Jennifer Rowley and John Farrow. Organizing knowledge: An Introduction to Managing Access to Information. Ashgate, 2000.

[77] T. Berners-Lee, J. Hendler, and O. Lassila. The semantic web. Scientific American, 284(5):28-37, May 2001.

[78] Birger Hjørland. Fundamentals of knowledge organization. Knowledge Organization, 30(2):87-111, 2004.

[79] Susan Leigh Star and Karen Ruhleder. Steps towards an ecology of infrastructure: complex problems in design and access for large-scale collaborative systems. Information Systems Research, 7:111-133, 1996.

[80] Christine L. Borgman. From Gutenberg to the Global Information Infrastructure: Access to Information in the Networked World. MIT Press, Cambridge, MA and London, 2000.

[81] Vetenskapsradet. Om forskningens infrastrukturer inom humaniora och samhällsvetenskap i sverige. Technical Report 131-2004-8236, Vetenskapsradet, Stockholm, 2005.

[82] Susan Leigh Star. The Ethnography of Infrastructure. American Behavioral Scientist, 43(3):377-391, 1999. 


\section{Isto Huvila}

[83] Susan Leigh Star and Geoffrey C. Bowker. Work and infrastructure. Communications of the ACM, 38(9):41, 1995.

[84] Elin K. Jacob and Hanne Albrechtsen. Exploring the contexts of information behaviour, chapter When essence becomes function: post-structuralist implications for an ecological theory of organisational classification systems, pages 519-534. Taylor Graham Publishing, London, 1999.

[85] Elin K. Jacob. The everyday world of work: Two approaches to the investigation of classification in context. Journal of Documentation, 57(1):76-99, January 2001.

[86] Clare Beghtol. Semantic validity: Concepts of warrant in bibliographic classification systems. Library Resources and Technical Services, (April/June):109-125, 1986.

[87] Birger Hjørland. Empiricism, rationalism and positivism in library and information science. Journal of Documentation, 61(1):130-155, 2005.

[88] Bernd Frohmann. An investigation of the semantic bases of some theoretical principles of classification proposed by Austin and the CRG. Cataloging \& classification quarterly, 4(1):11-27, 1983.

[89] Martin Ward. Phenomenological warrant: The case for working from the user's viewpoint. Managing information, 7(9):68-71, 2000.

[90] Clare Beghtol. A proposed ethical warrant for global knowledge representation and organization systems. Journal of Documentation, 58(5):507-532, 2002.

[91] James J. Gibson. The senses considered as perceptual systems. Houghton Mifflin, 1966.

[92] James J. Gibson. The Ecological Approach to Visual Perception. Lawrence Erlbaum, 1986.

[93] Donald A. Norman. The psychology of everyday things. Basic Books, 1988.

[94] Klaus B. Baerentsen and Johan Trettvik. An activity theory approach to affordance. In NordiCHI '02: Proceedings of the second Nordic conference on Human-computer interaction, pages 51-60, ACM Press, New York, 2002.

[95] Yvonne Rogers. New theoretical approaches or human-computer interaction. Annual review of Information Science and Technology (ARIST), 38:87-143, 2004.

[96] Kirsty Williamson. Discovered by chance: The role of incidental information acquisition in an ecological model of information use. Library \& Information Science Research, 20(1):23-40, 1998.

[97] Bonnie A. Nardi and Vicki L. O’Day. Information ecologies: using technology with heart. MIT Press, Cambridge, MA, USA, 1999.

[98] Elizabeth Sadler and Lisa M. Given. Perceptions of affordance in an academic library: A qualitative study. In CAIS Conference Proceedings, London, Ontario, 2005.

[99] E.B. Sadler and L.M. Given. Affordance theory: a framework for graduate students’ information behavior. Journal of Documentation, 63(1):115-141, 2007.

[100] Birger Hjørland. Basic units in library and information science. In American Society for Information Science and Technology Annual Meeting, November 12-17, 2004, Providence, Rhode Island. Session: Document, Record, Work: The Basic Units of Analysis in Information Studies, 2004.

[101] A. MacIntosh-Murray and C.W. Choo. Information Behavior in the Context of Improving Patient Safety. Journal of the American Society for Information Science and Technology, 56(12):1332-1345, 2005.

[102] Donna Haraway. Situated knowledges: the science question in feminism and the privilege of partial perspective. Feminist Studies, 14(3):575-599, 1988.

[103] Elfreda A. Chatman. The impoverished life-world of outsiders. Journal of the American Society for Information Science, 47(3):193-206, 1996.

[104] Inger V. Eriksson and Markku I. Nurminen. Doing by learning: Embedded application systems. Journal of Organizational Computing, 1(4):323-339, 1991. 


\section{Isto Huvila}

[105] Marianne Lykke Nielsen. A framework for work task based thesaurus design. Journal of Documentation, 57(6):774-797, 2001.

[106] C. W. Choo. The knowing organization: How organizations use information to construct meaning, create knowledge and make decisions. International Journal of Information Management, 16(5):329-340, October 1996.

[107] Pierre Lévy. Qu’est-ce que le virtuel? La Découverte, Paris, 1998. 